Session 2003-913

\title{
Capturing History with Modern Technology Wright Flyer Replica Space Launch
}

\author{
Steven D. Harper, MS Eng, David G. Meyer, PE \\ Sinclair Community College
}

\begin{abstract}
\end{abstract}
Student interest in engineering technology has been in decline over the 10 past years. Today's students seek exciting career opportunities and can choose from a number of interesting and rewarding non-scientific disciplines. The need to show high school students that engineering offers rewarding career opportunities has never been stronger, with an estimated 400,000 unfilled jobs nationally. There is a tremendous need for future engineers. As stated in a Wall Street Journal article, the generation that put a man on the moon is retiring. NASA has more engineers over age 60 than under 30. There are currently more graduates in Parks \& Recreation than in Electrical Engineering. In addition, the Freshmen attrition rate among Engineering majors is 40\% (Wall Street Journal, June 7, 2002).

This paper presents a concept to energize students' interest in engineering technology through a "hands on" application of a variety of engineering skills. A replica of the Wright Brothers 1903 aircraft that made the first successful manned, powered flight will be launched into space to commemorate the 100th anniversary of this event. An interdisciplinary team of engineering technology students at Sinclair Community College has collaborated to manufacture a scale replica for the launch.

Sinclair's Aviation Technology (AVT) and Industrial Engineering Technology (IET) departments have led this project. The leadership team for the project was created from three Sinclair student organizations affiliated with the IET and AVT departments. These include the Sinclair Aviation Club, the Society of Manufacturing Engineers, and the Society of Plastics Engineers. These student groups gained support from local industry partners and others in the community. A partnership was established with the Dayton Air Show Education Committee to involve High School students and the Dayton Challenger Center provided involvement for middle and elementary school students. Home Based Arts (HBA) has provided direction and vision to initiate agreements with NASA and has secured a launch window for March 1, 2003.

Outcomes from this project included achievement of Sinclair's Core Competencies by Engineering Technology students and a measurable increase in student enrollment and retention rates. The competencies of problem solving, communication, teamwork, and citizenship were emphasized. Significant results include a growth in the Sinclair Aviation Club from 10 members last year to 29 members this year. Two new student groups were established in the IET department. 


\section{Project summary:}

- Computer Aided Design to develop the model required for the manufacturing process

- "Hands on" use of prototyping methods and equipment

- Plastic injection molding

- Project management skills and integration of multi-disciplinary teams

- Outreach both to community partners including industry, high schools, and others for intellectual contributions and learning opportunities 
This project was undertaken to address the decline in enrollment and the attrition rate in engineering technology programs that has been prevalent over the past 10 years. The concept sought to energize students' interest in engineering technology through a "hands on" application of a variety of engineering skills. The project theme was the creation of a replica of the Wright Brothers 1903 aircraft that made the first successful manned, powered flight for a launch into space to commemorate the 100 year anniversary of this event. Students collaborated to manufacture a scale replica for the launch.

The Wright Brothers were innovators, experimenters and hands-on practitioners who amazed the world with their unprecedented achievement. They paid attention to detail and methodically tested their ideas, recorded results and utilized the resources of the day. In most cases they used materials they were most familiar with and those readily available. Their method f systematic problem solving makes them the first true aeronautical engineers in addition to being the world's first pilots.

This project paralleled many of the same problem solving challenges the Wright Brothers faced over 100 years ago when they utilized the technology and resources of that era. The full size 1903 Wright had a wingspan of 40 feet -4 inches where the model the students developed ended up being much smaller. Materials chosen needed to be compatible with NASA's space launch requirements along with many other parameters. NASA required exact specifications in order to assure the model would be launched into space.

Funding

The authors of this paper received funding for this project from the Russell F. and Edith Oyer Jerd Engineering Innovation Award, a new program for classroom innovation at Sinclair Community College. The purpose of the Jerd Award is to ensure the continuation of a top quality innovative engineering technology faculty and staff who will constantly advance and improve both the content and the environment of learning in Sinclair's Engineering and Industrial Technologies programs. This award provided nearly $\$ 3000$ for materials and supplies to build the launch models. Regrettably, Dr. Russ Jerd passed away near the end of 2002 after a prolonged illness. Dr. Jerd will be missed by his friends at Sinclair Community College.

Project Plan

Resources from Sinclair's Aviation Technology, Industrial Engineering Technology, and other engineering technologies were utilized to accomplish this project. The leadership team for the project involved three Sinclair student organizations. These included the Sinclair Aviation Club, the newly formed Sinclair chapters of the Society of Manufacturing Engineers and the Society of Plastics Engineers. Collaboration with local industry partners included Home Based Arts (HBA) who provided the vision and initiated agreements with NASA. XonTech, Inc. provided access to advanced technology Coordinate Measuring Equipment. Students have secured a launch window with NASA for March1, 2003. The project schedule is shown in Figure 1. 


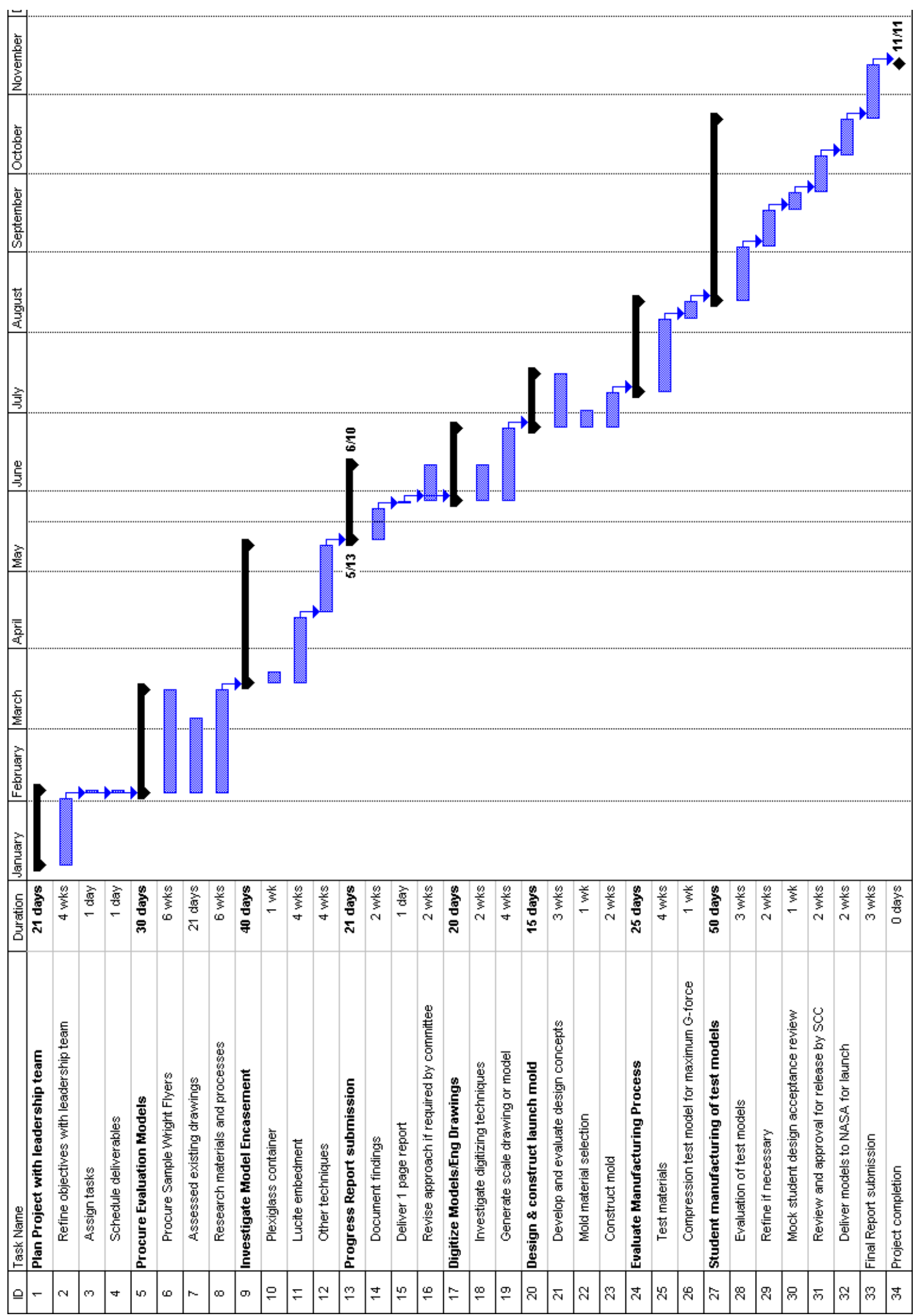

Figure 1 Project Schedule

Proceedings of the 2003 American Society for Engineering Education Annual Conference \& Exposition Copyright $@$ 2003, American Society for Engineering Education 


\section{Student Activities}

Leaders from each student organization that participated are listed in Table 1. Chris Combs directed the Sinclair Aviation Club activities and Melissa Tierney directed the activities for both the SME and SPE student chapters. Other students participated throughout the duration of the project. The Student Leadership Teams participated all design team activities and ensured that assigned tasks were accomplished as scheduled. The Student Directors assisted with project planning and learned about project management. All participants gained "hands on" experience with project elements such as procurement lead time, vendor delays, and other unforeseen hindrances. They developed solutions and "work arounds" just as they will have to do in the real world when they work in industry following graduation. The students have researched a number of topics including the NASA launch requirements and material properties.

\begin{tabular}{|l|l|}
\hline \multicolumn{1}{|c|}{ Aviation Technology } & \multicolumn{1}{c|}{ Industrial Engineering Technology } \\
\hline Chris Combs (Student Director) & Melissa Tierney (Student Director) \\
\hline Jamie Thomas & Chad Hagins \\
\hline Tonya Hampton-Koon & Paul Fleischmen \\
\hline Jamey Stutz & Brian Whitt \\
\hline Mike Brazel & Scott Weddell \\
\hline Tony Deemer & James Leach \\
\hline Mike Kester & Matt Lang \\
\hline Jake Mullins & James Miller \\
\hline Michael Suits & Brian Freeman \\
\hline Jeff Roemer & Jeremiah Marcum \\
\hline Jack Fink & Brendon Breitenstein \\
\hline Joseph Staley & Brian Frierott \\
\hline & Jason Hedrick \\
\hline & John Lux \\
\hline & Dylan Seats \\
\hline
\end{tabular}

Table 1 Student Leadership Teams

The student leadership developed two teams to handle Outreach and History Research. The Outreach Team's primary objective was to use the Wright Flyer project to let the community and aviation related businesses in the Dayton area know about Sinclair's aviation and engineering technology programs. This gave students from both departments an opportunity to network with people in the community and in local businesses that relate to their career interests. At the same time, the students provided a service to the community by informing local businesses of the opportunities for continued education at Sinclair and opportunities to recruit educated employees.

There has been a tremendous student response to this project. In the case of the Sinclair Aviation Club, it has increased membership from 5 members to 30 members, an increase of $600 \%$ ! The students have said that being on this project has been extremely rewarding, motivating them to work together as a team. The IET department was able to create two new engineering society student chapters, the Society of Plastics Engineers and the Society of 
Manufacturing Engineers. This is very exciting for a community college whose student body is made up of $100 \%$ commuter students.

Students explored a number of methods to construct a representative model of the Wright Flyer for the space launch. The investigations included CAD methods, materials, manufacturing processes, reverse engineering methods and equipment, rapid prototyping, representative scale models, and model encapsulation methods. Specific research areas are listed in the Table 2 below. Engineering requirements were derived from Baumeister and Marks (1967).

\begin{tabular}{|l|}
\hline Melt temperature of plastic model and embedment material \\
\hline "G" forces during launch \\
\hline Materials \\
\hline Drop impact test results \\
\hline Scale model with four inch wingspan \\
\hline Weight of finished product (less than two pounds) \\
\hline Electronic chip with 50,000 character storage capacity \\
\hline Material Safety Data Sheets for plastics \\
\hline
\end{tabular}

Table 2 Student Research Areas

Students researched representative scale models of the Wright Flyer as candidates for the NASA launch. One example is a model obtained from a Dayton area vendor (Figure 2). The students compared the models they found with engineering drawings (Figure 3) obtained from the Smithsonian Institute (Kitty Hawk Aeroplane, 1950) to validate their dimensional accuracy. These models served as a baseline for reversing the three dimensional data required to create a Computer Aided Design (CAD) model of the Wright Flyer. The students gained familiarity with 3-D digitizing equipment and methods and applied their knowledge of computers and CAD software to build the 3-D model.

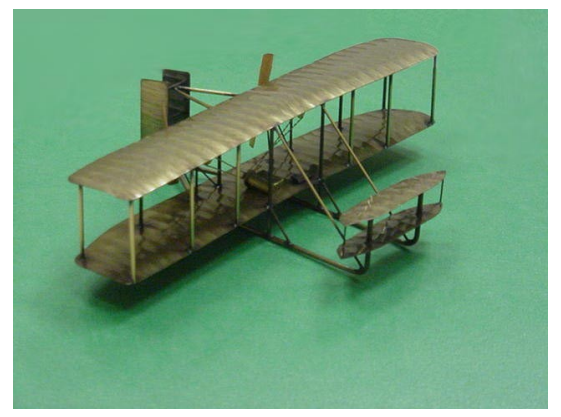

Figure 2 Wright Flyer Scale Model 


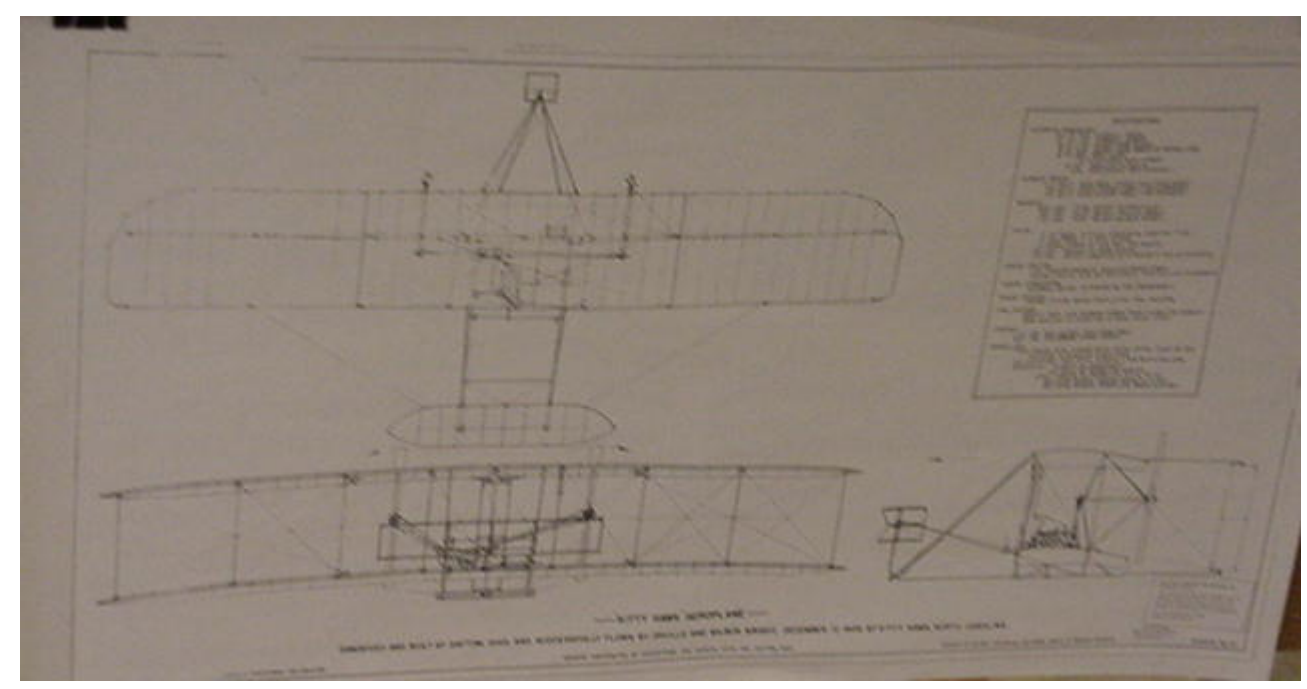

Figure 3 Kitty Hawk Aeroplane Engineering Drawing

The students conducted a literature search on the state-of-the-art of rapid prototyping technology to add to their knowledge of manufacturing processes. Manufacturing methods and materials listed in Table 3 were evaluated by the students. The student teams made site visits to Sinclair's industry partners that use some of these processes to observe the operation of the technologies. Together with faculty and industry mentors, the students were able to help select the best manufacturing option based on production accuracy, cost, schedule, and access to equipment.

The student leadership teams also assessed model materials required for the rapid prototyping process. Material specifications had to meet NASA launch requirements. Discussions on environmental impacts and other loss management factors taught the students about the cost-benefit analyses industries use to evaluate production alternatives.

\begin{tabular}{|l|}
\hline Investment casting \\
\hline Composites (Matthews and Rawlings, 1999) \\
\hline Wood construction \\
\hline Wood/fabric construction \\
\hline Metal construction \\
\hline Plastics construction \\
\hline Combinations of above processes \\
\hline
\end{tabular}

Table 3 Manufacturing Methods and Materials

To match NASA specifications exactly, Sinclair contacted NASA many times during the development of project to insure that our specifications matched their requirements exactly. The concept evolved from consideration of a half scale model followed by evaluation of a candidate $1 / 8$ scale model to the final 6 -inch wingspan or approximately $1 / 80$ scale.

The 6-inch model was designed using CAD modeling techniques. Construction of prototypes proved that this small size was very delicate requiring the pieces to be meticulously crafted and bonded together. The early models weighed in at 8 ounces, exceeding NASA's 
payload specification. Our letter writing campaign with NASA finally came to an end after submitting material, size and weight variables with CAD drawings and letting NASA select their desired parameters. CAD drawings of the final product are shown in Figure 4, Figure 5, and Figure 6. The launch article delivered to NASA is shown in Figure 7.

Commercial digital scanning technology that can electronically capture the three dimensional coordinates of representative scale articles was explored by the student teams. This technology was intended to permit data to be transferred into CAD software where CAD representations of the production models can be developed. XonTech, Inc., a Dayton, Ohio based business, offered the use of their Coordinate Measuring Machine (CMM) to attempt to reverse engineer a 3-D model for this project. After several attempts, the models proved to be too intricate and too undersized to benefit from the application of this technology.

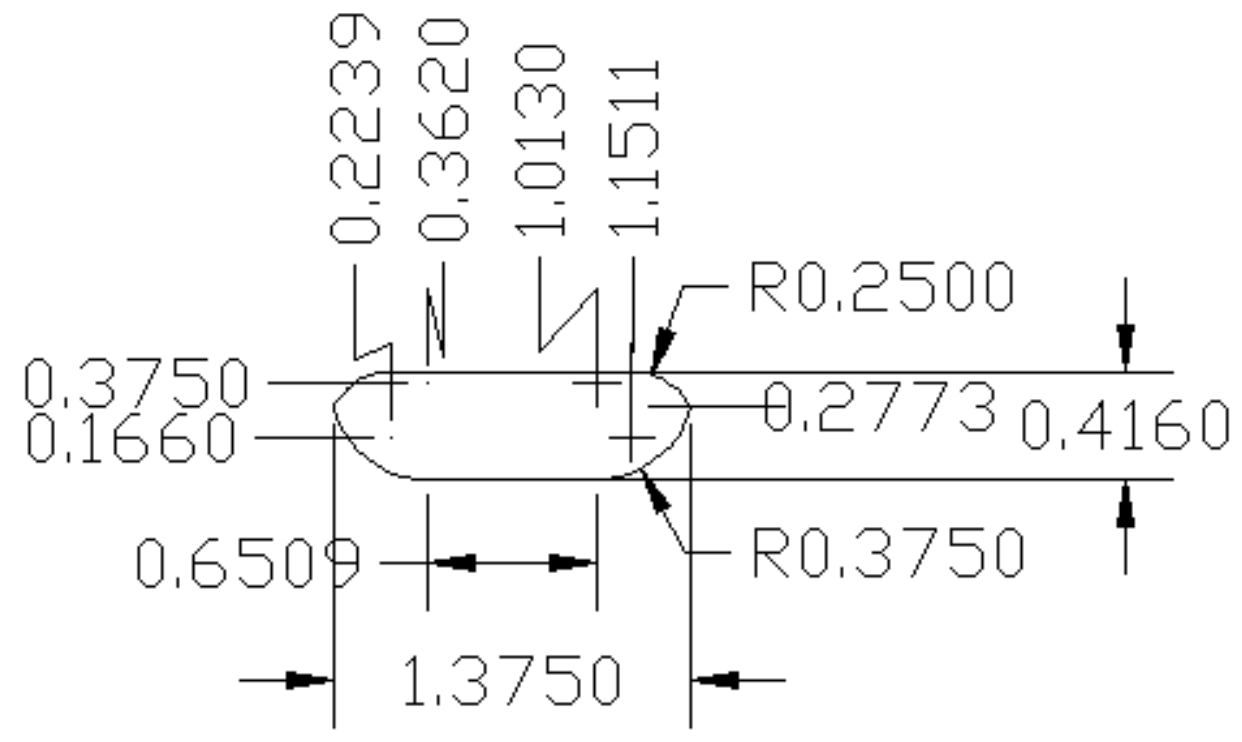

Figure 4 Horizontal Stabilizer

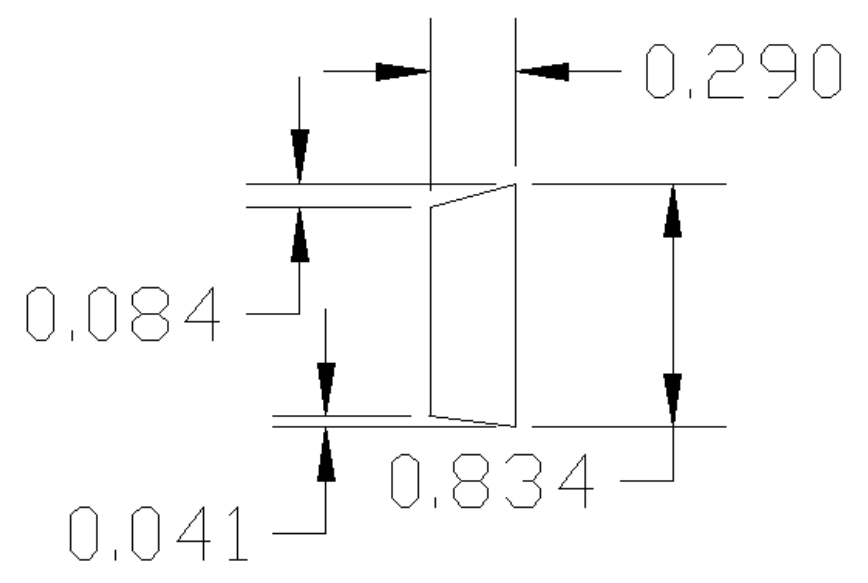

Figure 5 Rudder 


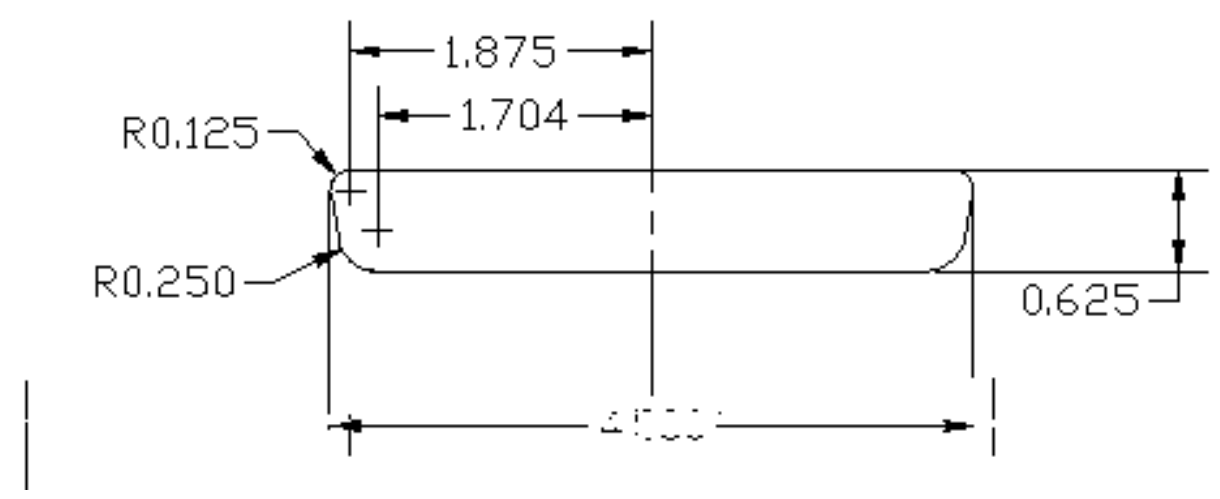

Figure 6 Wing

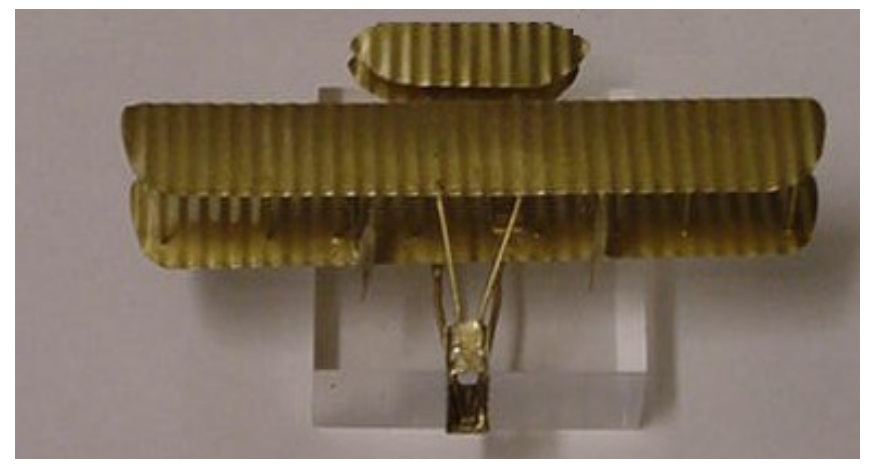

Figure 7 NASA Launch Article

The student teams were required to analyze the vibration and acceleration loads that will be placed on the model during the launch. The results of this analysis were used to specify the requirements for the launch mold necessary to encase and protect the model during the launch into space. Injection molding techniques and equipment were evaluated to see if they provide adequate protection of the model for launch into orbit on NASA's space shuttle and for reentry into the earth's atmosphere. Research on NASA payload requirements and the forces the payload will experience provided "real world" experience for our students on the difficulties of meeting customer requirements.

Systems engineering principles were implemented by the students to ensure that all requirements and specifications were addressed during the design process. Thorough understanding of the requirements provided the necessary data to validate the model to ensure that production articles achieved the objectives for the project.

Candidate materials for the models included metals, thermoplastics, and thermoset materials. Students determined that a metal replica would be the best material. It was the lowest cost to produce and met the mission requirements for material properties.

In order to withstand the severe environment imposed by a spacecraft launch, the students found that the models needed to be encased in order to be protected. Students selected from acrylics, polyurethane, polycarbonate, and others to match encasement materials with model materials. 
Processes Explored

While we were working with NASA to finalize the launch model specifications, many processes were evaluated for the models manufacturability and total costs. More than 80 materials/processes/tests and process steps were considered before arriving at our final model. Table 4 lists the engineering technologies explored to bring this project to fruition. Baumeister and Marks (1967) provided much of the background material for these processes.

\begin{tabular}{|l|l|l|}
\hline CAD & Metal stamping & Plastic casting \\
\hline Rapid prototyping & $\begin{array}{l}\text { Gold plating (Chromium } \\
\text { Plating, 1954 and Strohom, } \\
1971 \text { ) }\end{array}$ & Plastic embedment \\
\hline Coordinate measuring machine & Metal forming & Welding (TIG \& MIG) \\
\hline Reverse engineering & Chemical cleaning & $\begin{array}{l}\text { Soldering (soldering Tips, } \\
\text { 1999) }\end{array}$ \\
\hline Drafting & Metal shearing & Painting \\
\hline Casting & Material cutoff & Gluing \\
\hline Composites construction & $\begin{array}{l}\text { Metal annealing (to form } \\
\text { wing ribs) }\end{array}$ & Mechanical bonding \\
\hline Construction technique & Form dies & $\begin{array}{l}\text { Fixture design (Die } \\
\text { Design Handbook, 1965) }\end{array}$ \\
\hline Investment casting & Urethane form material & Material layout \\
\hline Plastic materials & $\begin{array}{l}\text { High pressure hydraulic } \\
\text { pressing }\end{array}$ & $\begin{array}{l}\text { Impact testing } \\
\text { (Richardson and } \\
\text { Lockensgard, 1997) }\end{array}$ \\
\hline Injection molding & Polishing & $\begin{array}{l}\text { Stress testing (Richardson } \\
\text { and Lockensgard, 1997) }\end{array}$ \\
\hline Rotational molding & Sanding (six process steps) & $\begin{array}{l}\text { Crush/load testing } \\
\text { (Richardson and } \\
\text { Lockensgard, 1997) }\end{array}$ \\
\hline
\end{tabular}

Table 4 Engineering Technologies

Finally NASA informed us that the model material could be brass, the weight had to be under one ounce, wingspan could not exceed $4 \frac{1 / 4}{4}$ inches in length, and the model had to be scaled to the 1903 Weight Flyer. To accomplish this we standardized our prototype on a 4-inch wingspan to further attain a weight reduction. By removing more brass material we met the weight requirement. With our processes and fixturing in place and material cut to scale we started the assembly procedures to mass-produce the models.

Assembly Process

The assembly process needed detail-oriented students willing to explore different fixturing and manufacturing techniques. Everyone agreed that the soldering process worked best, after trying TIG welding. All fixture concepts started as sketches then went to drawings before students built the final versions. The fixtures built include material holding for scribing, 
flat shear, round stock shear, and assembly. Some real creative students used rubber bands, duct tape and wire to secure the parts for the assembly process. Many students associated this assembly process to the first time they learned to ride a bicycle. A display of the assembly process and tooling is shown in Figure 8.

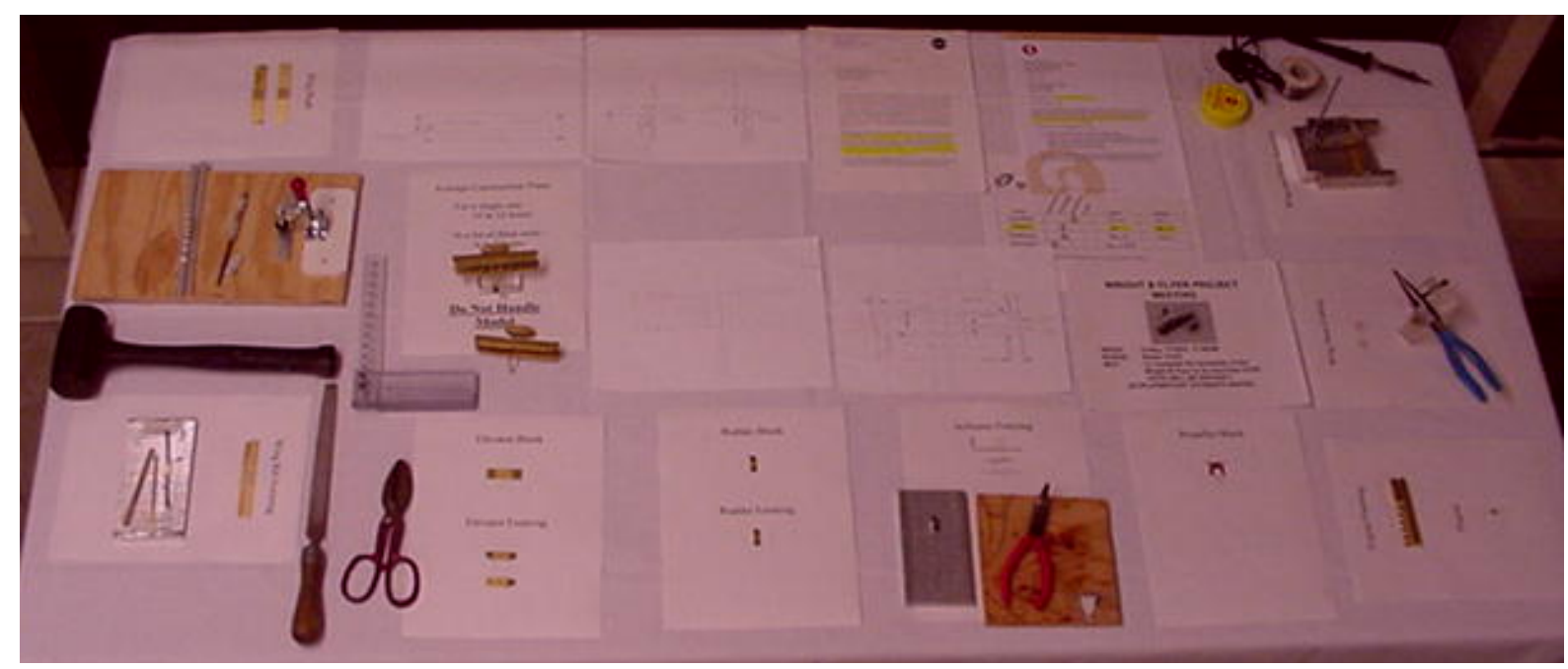

Figure 8 Assembly Process and Tooling

\section{Project Outcomes}

After assembly the final process learned through trial and error was plastic embedment, which was a Sinclair Community College requirement. To do this an autoclave was needed so the students along with faulty designed and built an ASME coded (Baumeister and Marks, 1967) pressure vessel for approximately $\$ 1,000$ (Figure 9). This autoclaving (pressure and temperature) process starts with solid Lucite resin and methyl methacrylate monomer being precisely weighed and mixed, then placed into the autoclave. A vacuum is pulled on closed vessel for 15 minutes to remove air, then nitrogen charges the vessel to 250 PSI while heat is applied. When temperature reaches 300 degrees F. a steady state is maintained for approximately 4 hours, then cooled to room temperature. This process was self-taught by students and faculty assistance testing samples of various sizes, weights and material proportions (Lucite Acrylic Resins, 2002). 


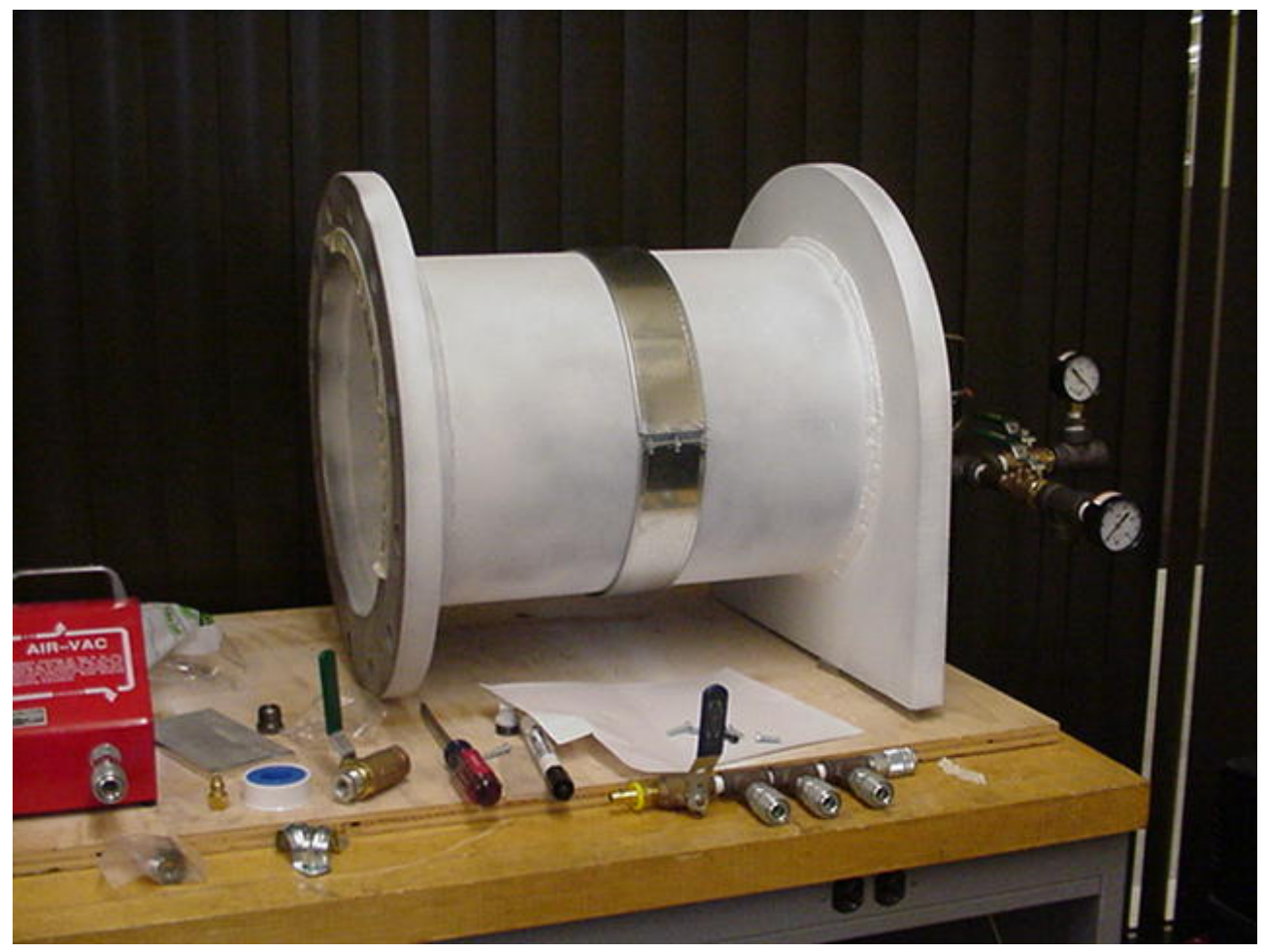

Figure 9 Autoclave

The students indeed followed in the path of the Wright brothers by testing, documenting results and using the technology of the day to meet customer requirements. Many times we found students displaying creativity and supporting each other to complete the tasks. In costing this project students learned that many times over the simpler processes were the least costly. Cost is an important outcome and we were measuring material, fixtures, tooling, and assembly costs to be able to pass on our costs to the customer. Principally NASA is the customer with the final weight and size limitations. Another customer is Sinclair Community College where proceeds could support a scholarship program.

Desired outcomes of this project were achievement of Sinclair's Core Competencies for Engineering Technology students and a measurable increase in student participation in on campus projects. The competencies of problem solving, communication, teamwork, and citizenship were specifically been emphasized.

The results of this effort have exceeded expectations. The students' enthusiasm for this project is as high now as it was when the project began. The students met frequently outside the classroom to work on it. Clearly their communications skills and ability to collaborate as a team have been impacted positively by this project. Their problem solving skills were refined by their research initiatives on the history of the Wright Flyer, manufacturing methods, and materials. In the area of citizenship, the students are seeking opportunities to involve the Dayton community and area High Schools in the project to promote good will and educational opportunities. They will continue this effort through collaboration with the Dayton Air Show Education Committee and area High Schools by offering a competition for these schools to build a 1/10 scale model of the Wright Flyer. Winning entries will displayed by Sinclair Community College at the Air 
Show in July of 2003 as the whole world celebrates 100 years of powered flight and Dayton's own aviation pioneers, the Wright Brothers.

This project has been a catalyst for attracting new students to the student organizations supporting this effort. The aviation club membership has increase by $600 \%$. The Industrial Engineering Technology department was able to establish student chapters of both the Society of Plastics Engineers and the Society of Manufacturing Engineers. The project has had a positive impact on the plastics program where enrollment has increased by $34 \%$. Now that the processes have been established and models are being built, the Women In Engineering Technology (WIET) students will become involved with limited production of the Wright Flyer replicas.

With the leadership of the aviation technology and industrial engineering technology faculty, this project has provided the students with a greater understanding of the many manufacturing processes available to create scale models for use in industry. They have learned how important the information gathering stage of a project is in order to achieve a cost effective, workable solution. They have gained perspective on the significance of meeting customer requirements in an engineering technology project.

This project started as an innovation award and since has involved students, faculty, many outside supporters of the project, and resources from companies who wished to contribute ideas or expertise. The students learned the high value of communication and collaboration among all team members. As a final note the students were able to see the project develop from the visionary stage, through the Research and Development phase, the prototyping, and finally the manufacturing phase. Rarely does this occur in a 2-year community college.

Capturing History with Modern Technology will conclude on March 1, 2003 with a launch of the final product on NASA's space shuttle Atlantis, Space Transportation System (STS) mission number 114. 
Bibliography

Baumeister and Marks (1967). Standard Handbook for Mechanical Engineers, $7^{\text {th }}$ Ed. McGraw-Hill. New York

Chromium Plating (1954). Robert Draper, Ltd. Middlesex, England.

Combs, Christopher (2002). Wright Flyer Project Summary. Written communiqué.

Die Design Handbook $2^{\text {nd }} E d$. (1965). Society of Manufacturing Engineers. McGraw-Hill. New York

Kitty Hawk Aeroplane Aircraft Drawing A-1 (1950). National Air and Space Museum. Sutland, MD.

Lucite Acrylic Resins. Retrieved July 19, 2002 from www.ineosacrylics.com.

Mathews and Rowlings (1999). Composite Materials: Engineering and Science. Woodhead Publishing, Ltd. Cambridge, England

Richardson and Lockensgard (1997). Industrial Plastics, $3^{\text {rd }}$ Ed. Delmar Publishers, Inc. New York

Solder Tips (1999). Home Depot.

Strohom, A. K. (1971). Electroplating and Engraving $3^{\text {rd }}$ Ed. Van Nostrand Reinhold Co., New York.

Wall Street Journal (June 7, 2002). As We Lose Engineers, Who Will Take Us Into the Future? p. B1

Steven D. Harper is the Chairperson for Aviation Technology and Automation \& Control Technology at Sinclair Community College. He has a Masters degree in Systems Engineering and over 20 years of experience with the military and commercial aerospace industry. At Sinclair, he has initiated High School outreach activities in robotics and aviation to interest young people in the fields of engineering, engineering technology, math, and science.

David G. Meyer is the Chairperson for Industrial, Manufacturing, and Plastics/Composites Engineering Technology at Sinclair Community College. Mr. Meyer is a licensed Professional Engineer with a Bachelors Degree in Industrial Technology and he will complete an MBA in the Fall of 2003. Mr. Meyer has over 30 years of industry experience and has been plant manager for a fortune 500 company. At Sinclair he has pioneered a new curriculum in Six Sigma, a state of the art process improvement program. 